\title{
Harlequin syndrome in two athletes
}

\author{
K E Fallon, J J May
}

Br J Sports Med 2005;39:el (http://www.bisportmed.com/cgi/content/full/39/1/el). doi: 10.1136/bjsm.2004.012195

Two cases are reported of harlequin syndrome, a disorder of the sympathetic nervous system in which sweating and flushing of the skin in response to exercise is diminished. This condition is most likely to be first noticed in sporting situations.

$\mathrm{D}$ isorders of autonomic function are rare in the sporting community, a focal sympathetic defect having been reported only once previously in an athlete. ${ }^{1}$ We present two cases of harlequin syndrome, a benign condition caused by autonomic dysfunction affecting sweating and flushing on the face and, in one of our cases, the upper limb and upper chest.

\section{CASE REPORT 1}

An 18 year old elite female basketball player presented after her team mates had noticed that, during training, one side of her face flushed and sweated and the other remained pale and dry. The patient was otherwise asymptomatic and her medical history involved only minor training related injuries and excision of a sixth left toe. Her only medication was the oral contraceptive pill and she did not smoke or consume alcohol. There was no family history of similar problems.

Clinical examination at rest was normal. In particular, the peripheral tendon reflexes were normal, as were the pupillary responses to light and accommodation.

After exercise (running for 90 seconds in direct sunlight after an indoor basketball training session) in conditions of $26^{\circ} \mathrm{C}$ temperature and $65 \%$ humidity, a clear line of demarcation could be seen on the face. On the left side, normal vasodilatation and sweating occurred whereas the right side remained of normal colour and no sweating was noted. The whole left arm and upper anterior chest to a level about $2 \mathrm{~cm}$ below the clavicle was similarly affected.

A clinical diagnosis of harlequin syndrome was made. A magnetic resonance imaging (MRI) scan of the lower cervical and upper thoracic cord and of the area of the cervical and thoracic sympathetic outflow was normal. Clinical photography performed after 15 minutes of exercise on a treadmill at $6 \mathrm{~min} / \mathrm{km}$ and $5 \%$ grade with ambient temperature of $35.5^{\circ} \mathrm{C}$ and $47 \%$ relative humidity revealed only minimal asymmetry in skin colour, but total absence of sweating on the right side of the face (fig 1). A thermogram scan performed after 20 minutes rest at $22^{\circ} \mathrm{C}$ and $70 \%$ humidity revealed no facial thermal asymmetry (fig 2A). After 10 minutes of cycling, the left of the face was warmer by $2-3^{\circ} \mathrm{C}$ (fig 2B), and, after an additional five minutes of running in direct sunlight, the left of the face was warmer by $3-4^{\circ} \mathrm{C}$ (fig $2 \mathrm{C}$ ). These temperature differentials were accompanied by left hemifacial flushing and sweating.

\section{CASE REPORT 2}

In the second case, a 51 year old woman presented with a six month history of hemifacial flushing after running. She had also noticed it after taking a hot bath. No asymmetry had been noticed in the limbs or on the trunk. There was no history of ptosis. The medical history included classical migraine, hypertension, and Raynaud's phenomenon. The only drugs being taken were indapamide and norethisterone/ oestradiol.

Clinical examination at rest was normal, as were MRI scans of the brain and cervical and thoracic spinal cord and nerve roots. A chest radiograph was also normal.

\section{DISCUSSION}

Harlequin syndrome is caused by autonomic dysfunction affecting sweating and flushing of the face and less commonly, as in one of our cases, the upper limb and upper chest. Deficits in these signs in response to heating or exercise are most commonly seen in Horner's syndrome (ptosis, miosis, enophthalmos, and anhidrosis of the face and upper limb) but also occur in the rare Ross's syndrome, in association with the classical findings of Holmes-Aide syndrome, tonic pupils, and hyporeflexia. ${ }^{2}$

In most cases, no cause is found but cases have been described in association with a superior mediastinal neurinoma, ${ }^{3}$ spinal invasion of a left apical lung cancer, ${ }^{4}$ and internal jugular vein catheterisation. ${ }^{5}$

Heat induced facial sweating and flushing is mediated by the sympathetic nervous system with sudomotor and vasomotor sympathetic fibres exiting the spinal cord through the second and third thoracic roots. ${ }^{6}$ It is therefore reasonable to suspect that the defect responsible for the clinical signs is to be found in the region of the thoracic sympathetic outflow.

The first major investigation of this syndrome was published in 1988 when Lance and colleagues described five patients who complained of sudden onset of unilateral facial flushing during exercise or in hot conditions. They described this as harlequin syndrome, as it was reminiscent of the "harlequin colour change" described in newborns where flushing occurs as the result of vasomotor instability in the dependent part of the body. ${ }^{7}$ To avoid confusion, it should be noted that the term harlequin syndrome has also been used

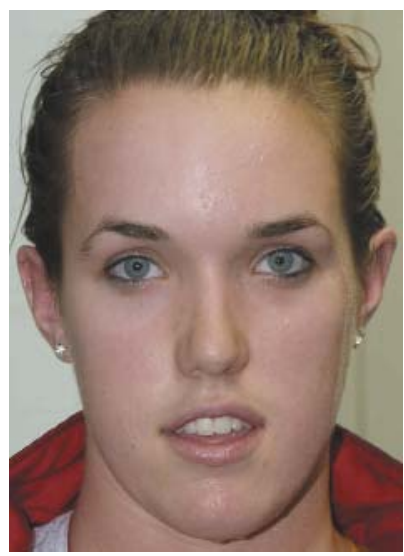

Figure 1 Facial appearance affer exercise in case 1 showing asymmetry of sweating on the forehead and chin. 

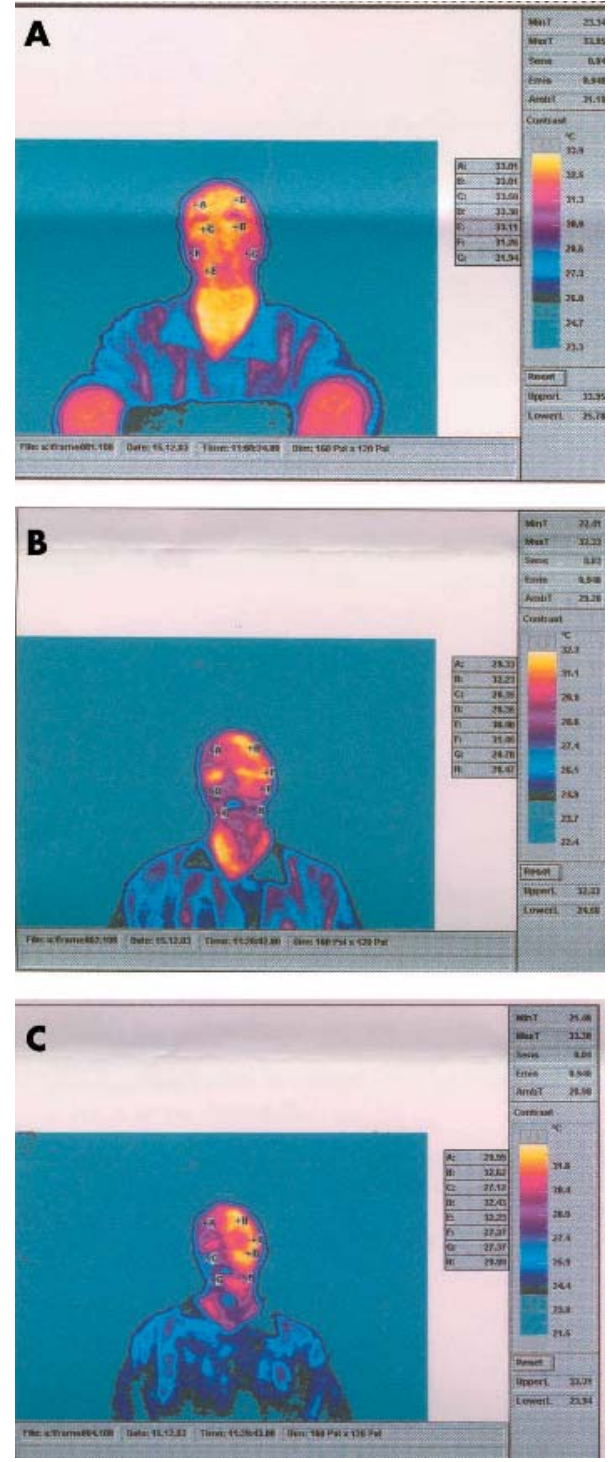

Figure 2 (A) Thermogram scan at rest. (B) Thermogram scan after cycling. (C) Thermogram scan after additional running in direct sunlight.

for an autosomal recessive skin disorder which represents the most severe form of congenital ichythyosis. ${ }^{8}$

In the group described by Lance et al, flushing and sweating in response to heat and emotional stimuli were impaired on the non-flushing side of the forehead in all five, and sweating and flushing after ingestion of spicy food (gustatory sweating) was increased on that side in four. Asymmetry of response was not noted on the trunk or limbs. In four of the cases, after computed tomography and MRI scans no structural lesion was found, and, in one, a brainstem infarct was suspected. A defect in the sympathetic supply to the face was postulated, and it was suggested that this may have been due to occlusion of the anterior radicular artery at the third thoracic segment. ${ }^{7}$

Further study of two of these patients and two others in 1998 involving assessment of ocular responses to phenylephrine and pilocarpine suggested that preganglionic or postganglionic cervical sympathetic fibres, and parasympathetic neurones in the ciliary ganglia are compromised in harlequin syndrome. One of the four patients did not show a parasympathetic deficit and presumably had an isolated sympathetic dysfunction. ${ }^{9}$

Clinical examination in suspected cases should particularly include a search for pathology in the area of the thoracic sympathetic outflow and assessment of pupillary responses and deep tendon reflexes.

In cases with no obvious underlying lesion, investigation should include MRI scanning of the cervicothoracic cord and the area of the thoracic sympathetic chain.

In idiopathic cases, usually no treatment is required, but symmetry could be restored by contralateral sympathectomy. In our patients, simple explanation of the pathophysiology and benign nature of the condition was all that was required.

In conclusion, we present two cases of a rare disorder of the sympathetic nervous system. This condition should be of interest to sports physicians as it is during exercise that the signs are likely to be first noticed.

\section{Authors' affiliations \\ K E Fallon, Australian Institute of Sport, Belconnen, ACT, Australia J J May, The Sports Medicine Centre, Turner, ACT, Australia}

Correspondence to: Associate Professor Fallon, Department of Sports Medicine, Australian Institute of Sport, PO Box 176, Belconnen, ACT 2616, Australia; fallonk@ausport.gov.au

Accepted 6 April 2004

Conflict of interests: none declared

\section{REFERENCES}

1 Corbett M, Abernethy DA. Harlequin syndrome. J Neurol Neurosurg Psychiatry 1999;66:544

2 Shin RK, Galetta SL, Ting TY, et al. Ross syndrome plus: beyond Horner, Holmes-Adie and harlequin. Neurology 2000;55:1841-6.

3 Noda S. Harlequin syndrome due to superior mediastinal neurinoma. J Neurol Neurosurg Psychiatry 1991;8:744.

4 Umeki S, Tamai H, Yagi S, et al. Harlequin syndrome (unilateral flushing and sweating attack) due to a spinal invasion of a left apical lung cancer. Rinsho Shinkeigaku 1990:30:94-9.

5 Coleman PJ, Goddard JM. Harlequin syndrome following internal jugular vein catheterisation in an adult under general anaesthetic. Anesthesiology 2002;97:1041.

6 Drummond PD. Sweating and vascular responses in the face: normal regulation and dysfunction in migraine, cluster headache and harlequin syndrome. Clin Autnom Res 1994;4:273-85.

7 Lance JW, Drummond PD, Gandevia SC, et al. Harlequin syndrome: the sudden onset of unilateral flushing and sweating. J Neurol Neurosurg Psychiatry 1988;51:635-42.

8 Chua CN, Ainsworth J. Ocular management of harlequin syndrome. Arch Ophthalmol 2001;119:454-5.

9 Drummond PD, Lance JW. Site of autonomic deficit in Harlequin syndrome: local autonomic failure affecting the arm and face. Ann Neurol 1993;34:814-19. 